\title{
Undergraduate Chinese students' perspectives on Gaokao examination: Strengths, weaknesses, and implications
}

\section{Muthanna, Abdulghani $\bowtie$}

Institute for International and Comparative Education, Educational Leadership and Policy, Beijing Normal University, Beijing, China (Am96715@gmail.com)

Sang, Guoyuan

Center for Teacher Education Research, Beijing Normal University, Beijing, China (guoyuan.sang@bnu.edu.cn)

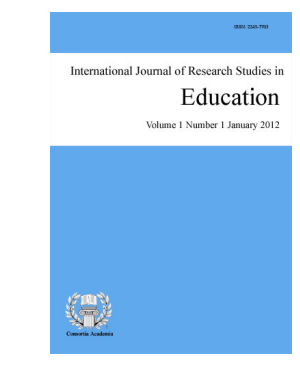

ISSN: $2243-7703$ Online ISSN: 2243-7711

OPEN ACCESS

Received: 16 May 2015

\section{Abstract}

Education policy makers should concern stakeholders' views on policy implementation, especially those who experienced related policies. In this study, the authors explored the undergraduate Chinese students' perspectives on Gaokao that is the national college entrance examination (NCEE) in China. The critical review of previous works, several group discussions with educators and students, and semi-structured interviews with ten undergraduate students revealed the presence of a few strengths but several weaknesses of the Gaokao examination policy. The existence of several weaknesses in such policy necessitates an immediate reform with a special focus on discovering and fostering talents, encouraging students' autonomy, and establishing students' creative, critical thinking and awareness. Further, among a few implications, the decentralization approach of education decision-making is suggested for Chinese higher education institutions.

Keywords: Gaokao; examination policy; students' perspectives; Chinese education; Chinese undergraduates 


\section{Undergraduate Chinese students' perspectives on Gaokao examination: Strengths, weaknesses, and implications}

\section{Introduction}

It is common sense that education is the key dimension in the development of any country and the quality promotion of education demands ongoing reforms. However, reforms in education are not well considered until that country goes through economic or political issues (Paine \& Zeichner, 2012). These reforms in education start with reforms in educational policies by considering essential research findings. In theory and practice, policy and implementation support each other; the implementation process is essentially an indispensible element of the policy-making process (Hogwood \& Gunn, 1984). In other words, to assess whether the policy goals are achievable and well planned, policy-makers must pay attention to implementers' evaluations. Implementation studies are supposed to be continuously conducted in order to reform the policy goals and develop a sound education policy that increases and strengthens the education quality (Gerston, 2004; Pressman \& Wildavsky, 1973). Influences on implementation are shaped by "macro- (policy-level) and micro-(implementation-level)" issues. This indicates that implementation is seen as a "mutual adaptation" where implementers try to "reconcile conditions in their micro-level context with macro-level demands" (Berman \& McLaughlin, 1976-1978 as cited in Honig, 2006, p. 7).

In China, there is an education policy concerning admission into higher education institutions. This policy is known as 'the Gaokao Examination Policy' that was adopted in 1952 by the newly founded People's Republic of China. Gaokao, the national college entrance exam (NCEE), is interpreted as a "high-stake test", and is a curriculum-based exam that "tests students' mastery of the subjects taught in high school" (Bai, Chi, \& Qian, 2014 , p. 634). The test is considered to be the world's first standardized educational examination. It annually takes place in June. The event of such a test could seriously be the most critical one in the lives of the Chinese youth and parents who care a lot about their children's future. Millions of students apply for such a test. In 2013, for example, about "9.4 million graduating seniors across China" took this test (Schroch, 2014).

In current China, the test score is the decision maker of an examinee's college. In other words, the higher the score, the higher ranking university will be selected for that score achiever. The scores as the current Gaokao policy stipulates follow this format: " $3+\mathrm{X}$ ". The "3" stands for a total of 450 points distributed as follows: 150 for Chinese, 150 for Math, and 150 for foreign language (mainly English). The " $\mathrm{X}$ " element refers to the other 300 points that are granted on one comprehensive subjects test. However, the test applicants have the option to choose among subjects depending on their future interests. Test applicants interested in science and engineering majors, for instance, would undergo a subject test including physics, chemistry, and biology. Other applicants interested in liberal arts would, on the other hand, take a subject test related to history, politics, and geography (Liu \& Wu, 2006). This might sometimes go against individuals' interests. For instance, the test achiever might want to join a particular university in her/his hometown but s/he is not allowed due to her/his low test achievement. This kind of test could be considered both placement and achievement test at the same time. Above all, it is very surprising that the certificate of such a test is valid only for one year. In case an applicant is having any issue such as illness, traveling abroad or any other reason, they need to take the test again next year.

This paper focuses on investigating the perspectives of undergraduate Chinese students towards the Gaokao examination policy. The research questions of this paper are: 1) what are the perspectives of the undergraduate Chinese students towards the Gaokao examination policy? And 2) why they hold such perspectives? The significance of this study lies in the findings that work as answers to these questions and how tests' takers view such Gaokao examination policy. The study is also significant as it provides implications, based on the findings of this study and the critical analysis of previous literature, to policy makers on the macro and micro levels for an urgent consideration to the voices of tests' takers and the reflection of their needs in the examination policy. The 
Chinese students' perspectives on Gaokao examination: Strengths, weaknesses, and implications

presence of some implications for teachers also strengthens the importance of this study. Following is a detailed literature review.

\section{Study Background}

Higher education is an important phase in any education system. It is the stage where professors can better re-shape or develop the characters of the programs' candidates (Karaman \& Tochon, 2007). Therefore, the necessary development of such an important stage critically demands a very well-developed policy and strategies that regulate and facilitate the learning-teaching process and effectively achieve its goals. In China, there is a strict policy concerning admission into higher education institutions, known as the 'Gaokao examination policy'. The following excerpt describes how the Gaokao exam works like a crucial gatekeeper for higher educational mobility in China:

The Gaokao was restored as a key mechanism of structuring higher education opportunities, and academic performance in the Gaokao, instead of political affiliation, became the decisive factor in access to higher education (Liu, 2013, p. 873).

The above script, as it reads, clearly shows how significant the Gaokao test is in deciding students' access to higher education institutions in China. The script also points to a serious issue of political affiliation whose existence anywhere in the world brings about a slow death to the education system. On the contrary, the author seems to be content with the presence of the Gaokao examination as a replacement to political affiliation.

The Ministry of Education in China determines two cut-off scores - which differ from one year to another as policy makers consider applicants' number and available positions -to enter higher education institutions. While the first cut-off score is associated with an entrance to prestigious universities, the second is considered the minimum score for entry into any university (Davey, Chuan, \& Higgins, 2007). This policy might lead to the trueness of the assumption that the Gaokao examination policy deprives Chinese universities from becoming independent and autonomous entities (You \& Hu, 2013) and might also make several Chinese universities go down in the reports of world-class university rankings.

Many other researchers have also criticized the Gaokao examination policy. Almost all scholars have exclusively studied the Gaokao system flaws with a view to improving it. While several studies exploring the aspects of the Gaokao test system in China were published in local journals in Chinese, only a few studies addressed the international scholarly community. Furthermore, all the studies the authors have reviewed are either review papers or studies based on the quantitative approach. There is no, according to the authors' knowledge, single study that adopts the qualitative approach to understand the students' perspectives who experienced the exam. For example, one review paper by Zhang, Zao, and Lei, (2012) referred to the Gaokao test as bedrock of China's higher education and the culprit for China's unsuccessful education policy to foster innovative talents. Likewise, Liu (2013) stated that Gaokao symbolically stands for a meritocratic selection that leaves no place for discovering talents from all social origins but rather favors "those from professional families, from urban developed areas and those who have better secondary schools" (p. 884).

Yan and Yao (2010) contended that Gaokao has few major drawbacks such as much focus on public courses (e.g. Chinese and English) rather than on professional courses (science courses). They suggested that the school curriculum should be changed according to the Gaokao testing system with much focus on profession. This means that the test should examine students' interests in different professions. It also implies that there should not be any compulsory courses tests. This is also confirmed by Long and Li (2008) who assumed the establishment of 'Gaokao system based on profession dividing policy'. In the same year, Zhao and Ma (2008) explained that Gaokao does not have much flexibility since it does not offer more opportunities and choices for students. Therefore, the authors suggested that China should make use of other successful practices of advanced nations through, for example, including the students' high school achievement grades in the universities admissions. This means that $50 \%$ of the university entrance should be based on the students' school achievement 
grades and the other $50 \%$ is given for the Gaokao test. Such a suggestion, as the authors of this study can see, might increase students' awareness towards effective learning as well as achieving high grades at high school classes; meanwhile, it might also decrease students' tension and fear towards the test of Gaokao.

Wang (2011) reported that Gaokao focuses on selecting government officers and not on discovering talents. According to him, the test of Gaokao works like that of the Imperial College Examination where the focus was on selecting officers and not fostering talents. Many students have had psychological problems and several suicide cases due to the pressures driven from the Gaokao examination (Yu \& Suen, 2005). Later, Long, and Li (2008) noted that Gaokao system is a barrier to individuals' socialization development as it makes students be obsessed with the Gaokao test preparation without any social interaction. The authors hoped that the test would not be confined to school curriculum but would focus on future education majors.

Very recently, Wu (2013) argued that Gaokao has several negatives and positives. But the presence of the negatives, according to him, necessitates the need for reforming the test. The author then proposed a plan for the Gaokao test system reformation. The plan has three focal parts: 1) the National High School Academic Performance Evaluation could better be employed instead of the Gaokao test, 2) universities could use their own evaluation criteria for admitting candidates after considering candidates' High School Grade Point Average (HSGPA) and comprehensive performance, and 3) research oriented universities can also implement their selection tests based on student's high school performance as well. This kind of reform was also proposed by Yan and Yao (2010). This form of proposal seems to be interesting and deserves attention from the Gaokao examination policy-makers.

As Gaokao is a very major event that attracts millions of families' interests and has become the focus of people's lives (Zhang \& Zha, 2010) in China, reform of Gaokao is urgently needed for a better spiritual and cultural lifestyle for all people (Lei, 2011). In the same year, Guo (2011) assumed that different universities should have different policies concerning students' admission. The author also emphasized that reforming Gaokao will also lead to a social and economic reform resulting in an increasing progress of all China.

To conclude, this critical literature review reveals that almost all researchers call for a reform of the Gaokao exam in way that reflects flexibility, students' autonomy, and critical thinking. In addition to confirming the findings of those researchers, the present study differs from previous works in the way that it has followed a rigorous qualitative-based inquiry for collecting and interpreting data. Another main difference lies in the use of semi-structured interviews that were well designed to get in-depth data concerning the issues under investigation.

\section{Research Design}

This is a qualitative case study that "contributes to policy formulation, implementation, and modification" (Macmillan \& Schumacher, 2010, p. 325). Within this qualitative approach, the authors triangulated data by adopting mainly two data collection tools. At the outset, the authors critically reviewed the existing literature related to the Gaokao examination policy, a very significant step for deepening the understanding of the issue under investigation. Taking the critical literature review into account, the authors developed a deeper awareness about the Gaokao system and how important the Gaokao examination is for the Chinese government and people. This awareness accompanied the authors during the whole process of investigation and helped to lead to effective discussions on the Gaokao examination policy and related issues with educators and post-graduate students. The discussions also helped the authors prepare semi-structured interviews. The authors first piloted the semi-structured interviews with three undergraduate students. After transcribing the interviews, a revision of the first draft was done, an action leading to the elimination and addition of some questions. After preparing the final version, the authors conducted the semi-structured interviews with ten participants who belong to different universities and different cities in origin as well. These participants are undergraduate students in different programs at three different universities in Beijing, China. The semi-structured interviews are effective in realizing and recognizing humans' perspectives expressed through language/interaction as well as movements 
Chinese students' perspectives on Gaokao examination: Strengths, weaknesses, and implications

(Seidman, 2006). The interviews started with general questions and gradually moved on to more specific questions as this technique helps in making the interviewees feel at ease (Fontana \& Frey, 2005; Macmillan \& Schumacher, 2010). The following table describes the profile of each participant.

\section{Table 1}

A Profile of the Study Participants

\begin{tabular}{lcccc}
\hline \multicolumn{1}{c}{ Pseudonyms } & Gender & Age & Provinces & Majors \\
\hline Moon & F & 21 & Beijing & Automation \\
Rain & F & 20 & Jiangsu & English Literature \\
Rainbow & F & 18 & Hebei & Environmental Science \\
Sun & F & 21 & Shandong & Material Science \& Engineering \\
Star & F & 20 & Guangdong & Software Engineering \\
Sam & M & 20 & Inner Mongolia & Electronic \& Information Engineering \\
Jaibreel & M & 20 & Guangdong & Electronic Engineering \\
Goldy & M & 18 & Jiangxi & Automation \\
Faith & M & 19 & Guangdong & Electronic Engineering \\
Rami & $\mathrm{M}$ & 19 & Beijing & Educational Technology \\
\hline
\end{tabular}

After transcribing the collected data carefully, the authors followed the Inductive Analysis Procedure in which they "synthesize and make meaning from the data, starting with specific data and ending with categories and patterns" (Mcmillan \& Schumacher, 2010, p. 367). Meanwhile, the authors employed the interpretive and reflective analysis techniques (Gall, Gall, \& Borg, 2003). Intensive readings of data helped in finding out similarities and differences of the respondents' answers and further helped in the coding process. The coding process also assisted in the emergence of several themes. Here is an explanation of the most important themes of the current study.

\section{Findings and Discussion}

The analysis of the semi-structured interviews resulted in the emergence of several themes. The most significant themes are presented below.

\subsection{Strengths and Weaknesses of Gaokao}

Success of education policy-makers is rooted in their continuous research for any constructive feedback concerning their policies. In other words, successful educational leaders or policy-makers have always benefitted from researchers' critical comments (they always care about critical comments as they struggle to improve their works). While the study participants predominantly discussed the weaknesses of the Gaokao examination policy, they also identified some areas to be strengths of the Gaokao testing system. All the participants agreed that Gaokao strengthens equity in China since all students are subjected to the same test. They also expressed that such a test leaves no space for the use of connections/friendship as such an issue is, according them, sometimes used in other situations in China. On the contrary, they stated that it is not fair in terms of its grading system. For example, Star said that "the test is fair for we all take the same test but it is not so for students with foreign IDs, who get extra points!" Another participant, Rainbow, stated that

The minority students are also beneficial; although they might get average score in the test; they are still allowed to join the universities they prefer. While it is impossible for us, the non-minority students, to be accepted to those high-ranking universities with such average scores.

This statement also points out to the viewpoint that this policy is not fair since all students are subjected to the same test but not following the same procedures of colleges' admissions except the disabled as they have natural disabilities. This above-mentioned statement goes parallel with what Davey et al. (2007, p. 389) also expressed in the following script: 
Some ethnic minorities, sportspeople, children, military personnel, the disabled, and certain other groups are given advantages in score requirements, and some students with unusual abilities maybe admitted via interview without the examination (as cited in Hannum, An, \& Cherng, 2011, p. 276).

The above statement of Davey et al. (2007) shows that there are many people who benefit from the Gaokao examination scoring policy. This might not be acceptable as all students are from the same country and should have equal rights. Although the minority students, according to Rami, "... have very limited access to educational resources, I still think this has nothing to do with the policy admission of colleges. We all students of China must have the same facilities and same grading system". This discourse explicates that minority students do not have similar educational facilities provided to other students. Meanwhile, it shows that the participant supports the importance of the students' equal treatment in the learning-teaching facilities and universities' admission criteria.

All participants admitted that the test encourages them to search for knowledge through different resources and this is a merit and they described the test as 'Memory-based Test'. In a way, the test strengthens memory as it mostly depends on memory skills, it does not, according to the interviewees, enhance creative and critical thinking. At the same time, they also emphasized that the test does not focus on profession development and selection. This confirms the findings of Yan and Yao (2010) who reported that the test focuses much on public courses (e.g. Chinese and English) rather than on professional courses (science courses). The findings also confirm those of Long and $\mathrm{Li}$ (2008) who assumed the establishment of 'Gaokao system based on profession dividing policy'.

Furthermore, the study participants contended that the test of Gaokao encourages the process of perseverance so long as all students are working hard to achieve the intended scores. They, however, pointed out to a very serious issue- the issue of students' being psychologically and socially pressured. On this issue, Sun discoursed:

I spent almost a year away from my family members, friends, mates, and even teachers; I was locking myself in my room preparing myself for the test. I had a mix of feelings then; a feeling of perseverance and that is OK but I felt also like I am living a world of my own, a world full of misery as all of them [parents, friends and teachers] expect me to achieve the best score. That was a lot of pressure on me!

Such a discourse illustrates how such expectations of parents and the community put much pressure on these students. Being excluded from the community is one of the main factors that lead to having psychological problems that might affect students' whole lives. Our findings confirm those of other scholars that such a test had led to the existence of many recorded cases of psychological problems and suicides (He, 2000; Yu \& Suen, 2005). Meanwhile, Siegel (2007) stated that Gaokao is the most pressure packed examination in the world while Lian (2011) stated that Gaokao, compared to the American test known as Students' Achievement Test (SAT), is more intensive in its competitiveness that results in the presence of great challenges in the exam. These exam challenges, according to Lian (2011), lead to the presence of the greatest numbers of exams' losers in the world.

To conclude, the authors note that Gaokao is rooted in the education system of China and cannot be abolished; however, due to the presence of many weaknesses, the authors call the education policy-makers in China to rethink how to minimize the dangers of such a test by giving some options to students in taking tests of particular subjects related to their future college interests and repeating the test twice a year. An education policy must be prepared in a way that facilitates ways for students and not becomes a barrier to their future. This Gaokao test policy reform is urgently needed with a focus on reaching the needs of parents and youths by giving equal opportunities to all students during all processes of schooling, testing, and scoring. The reform should also focus on giving equal cut-off scores in all provinces; otherwise, different universities in different provinces will demand different cut-off scores. And this issue, according to Wang and Chan (2005) might raise a geographic 
Chinese students' perspectives on Gaokao examination: Strengths, weaknesses, and implications

discrimination that needs rethinking on the part of education policy-makers.

\subsection{Focus of the Gaokao Test Reform}

The Gaokao test administered by the Ministry of Education is considered the first step towards students' success in China. The success in such a test will help in other future successes as it determines students' future universities and majors. This test has a long history and is deeply rooted in the education system of China. The Gaokao "reflected the modernizing state's own idealized self-image, which consistently invested old forms with revised subject matter" (Strauss, 1994, p. 219). Moreover, the Gaokao examination is oppressive as Wang (2005) commented that "there is an entire generation of angry young high school kids who live under the yoke of the oppressive system known as the College Entrance Examination (Gaokao)" (p. 192). Additionally, the exam of Gaokao engenders pressure to teachers who cannot be innovative in their teaching methods or reform the curriculum in high schools (Li \& Edward, 2013, 2014; Yan, 2014). On the contrary, such an exam cannot be abolished as our participants reported. They all agreed that there is no alternative for such a test and it is the only one that can fully assess students' knowledge of different subjects. Rami, a study participant, stated that the test has a lot to do with the Chinese culture and there is no way to get rid of it at all. Jaibreel also said that "this Gaokao test has a long history and all Chinese people are accustomed to it; it cannot be replaced!" These statements indicate that it is not easy at all to replace such a test for the unavailability of other tests that suit the Chinese history, culture, and beliefs. However, all participants agreed on the necessity for reforming the Gaokao examination policy.

The reform should foster many issues. For example, Rami said that the test should focus on "encouraging students to build the merit of creativity and critical thinking; the current test enriches memory only". This is important as it has become the focus of almost all education institutions worldwide. Creativity, critical thinking, and autonomy are central issues in education and should be fostered and encouraged from the early stages of education. Therefore, the test of Gaokao should also focus on these educational standards. Another interviewee, Moon, stated:

\section{The Gaokao test is OK but the problem is that it does not help us in developing our personalities well ... It does not focus on creating talented students. There are many talents in China who might get destroyed by such a test. In fact, the test does not examine whether I am talented or not.}

The above statement clearly shows that the participant is not happy with the current focus of the test that is memory-based test; it does not investigate whether students have talents or not. As the statement reads, personality development is not attained through this test for students get prepared for memorizing knowledge and certain facts, and excluded from society. All these factors make the development of students' personalities very slow if not backward. The discovery of talents in high schools, as we contend, is very significant and can also be known through well-designed tests. On this specific issue, Goldy also reported

We are too much concerned with the Gaokao since our primary schools. All family members and
school teachers instruct and concentrate on how to pass the Gaokao. We do not get a chance to
take care of our personalities or develop at least a particular talent. I know lots of classmates
who are really talented in many things but their talents are perished by the preparation for the
Gaokao.

The above discourse shows that the pressure students get from their families and schools' teachers makes it hard for them to develop personalities capable of dealing with today's world issues. Such a personality, based on continuous memorization preparation for tests, may continue in this direction and might find it very challenging to change later in life. It is warned; therefore, that such a process of learning will lead to adopting certain behavior patterns that are very difficult -if not impossible- to change. Test preparation does not leave students with any choice of finding out and developing their talents. It is the duty of the schools' principals and teachers 
to foster the discovery of talents in their students and try to improve these talents with the collaboration of those who have more power in decision-making. At later stages, the test will accomplish what teachers have discovered. In other words, the test should focus on discovering more talents and accordingly these talents should be well considered and cared for. Having a great number of talents and developing them, as the authors of this paper assume, will lead to the development of that country in many aspects. Here, Sun believed that

Without taking care of talents in our country, the country will always face many challenges. The country still needs many leaders, thinkers, developers, etc. in many institutions, fields, etc. and this can be achieved through selecting talented students. I am now an undergraduate student and going through the same test procedures. I wonder when they will take care of my thinking, when they will discover whether I am talented or not... There is something wrong in the Gaokao test and this needs reconsideration from not only education policy makers but administrative and teaching staff members, too.

This statement deserves attention. It indicates how it is necessary for a country to prepare new thinkers and/or leaders in different fields. Preparation of such leaders/thinkers will help the country reduce the challenges it is facing. In the above statement, the participant implies that she is not content with the Gaokao test since it is not designed for discovering whether students are talented or not. The participant also implies that such a system has become prevalent even in higher education institutions where there is little care given for discovering and developing talents. Higher education institutions have turned to be places where 'power' is utilized and students have to be loyal to such powers so that they would receive recognition and motivation. This emphasizes the following idea of Burke (2012) that

... motivation must be 'done' in the 'right' ways by the 'right' kinds of bodily and academic practices in order to gain access to (high status) higher education. This requires particular forms of being a person ... the power to be recognized as a 'motivated student' does not reside entirely with the individual because the recognition of 'motivation' is always tied to social practices and embodied identities (p. 130).

Moreover, the participant suggested that it is necessary to focus on discovering talents and developing them by making efforts from both education policy-makers who prepare schools' curricula and the Gaokao test and key implementers who implement such policies. To conclude, the authors of this paper emphasize that such perspectives are important and should be considered in the reform of education policy concerning curricula, tests, etc. Students' voice should be valued and talents' discovery and development should be implemented.

\section{Conclusions and Implications}

This study has focused on exploring the perspectives of undergraduate Chinese students towards the Gaokao examination policy. The students' perspectives are interesting as they all focus on the immediate reform of the Gaokao test. The findings highlight the presence of few positives but many negatives of Gaokao. These negatives of Gaokao call for an urgent reform of the test in a way that focuses on discovering and developing talents, fostering critical awareness and thinking, and encouraging students' autonomy. This can be achieved through reforming the policy concerning the schools' curriculum and then the policy of the test. The curriculum should focus on these issues the authors have mentioned and the test will just complement what the curriculum and teachers would achieve. The findings also emphasize the need for Chinese universities to be autonomous in admitting students and this might be a radical reform of the Gaokao examination policy. The achievement of these suggestions interpreted from the students' voices will help the country not to face many future challenges and achieve its goals easily and within a shorter period of time. Unless these suggestions are seriously taken by policy makers, students and teachers would continuously go through pressures that impede their innovations and the Gaokao exam would continuously be a symbol of threat for both students and teachers.

It is safe to imply important activities that will lead to the improvement of the Gaokao exam as well as the 
Chinese students' perspectives on Gaokao examination: Strengths, weaknesses, and implications

higher education institutions in China. First, education policy-makers need to rethink of all ways that increases the strengths of the Gaokao exam. One simple way is working hard to alleviate the weaknesses discussed in this study. Another way is to upgrade the high schools' curriculum in a way that matches with the Gaokao test and this demands further training to teachers. Teachers at high schools need to focus on the content rather than highlighting the activity of the Gaokao exam. This might lessen the students' pressure towards the exam. Less pressure, the authors believe, will lead to higher achievement in the exam. Further, it is safe to suggest that education policy-makers need to decentralize the education process in higher education institutions in China, an action that increases autonomy, self-dependence, and internal competition. This will then lead universities to have their own Gaokao exam but based on programs students prefer to major in.

Acknowledgement: This research was funded by "the Fundamental Research Funds for the Central Universities" and the 2014 Comprehensive Discipline Construction Fund of Faculty of Education, Beijing Normal University.

\section{References}

Bai, C., Chi, W., \& Qian, X. (2014). Do college entrance examination scores predict undergraduate GPAs? A tale of two universities. China Economic Review, 30, 632-674. http://dx.doi.org/10.1016/j.chieco.2013.08.005

Burke, P. J. (2012). Lifting barriers: challenging differences in shifting cultural, political, and economic frameworks. In J. P. Burke (Ed.), The right to higher education: Beyond widening participation (pp. 126-140). Milton Park, Abingdon, Oxon; New York: Routledge.

Davey, G., Chuan, D., \& Higgins, L. (2007). The university entrance examination system in China. Journal of Further and Higher Education, 31(4), 385-396. http://dx.doi.org/10.1080/03098770701625761

Fontana, A., \& Frey, J. H. (2005). The interview: From neutral stance to political involvement. In N. K. Denzin. \&, Y. S. Lincoln (Eds.), Handbook of qualitative research (pp. 695-727). Sage Publications, Inc. United Kingdom: London.

Gall, M. D., Gall, J. P., \& Borg, W. R. (2003). Educational research: An introduction (7th ed.), Allyn \& Bacon: Boston.

Gerston, L. N. (2004). Public policymaking: Process and principles (2nd ed.), Armonk, NY: M.E. Sharpe.

Guo, S. (2011). Trend of Chinese Gaokao system reformation. Economic Research Guide, 5, 198-199.

Hannum, E., An, X., \& Cherng, H. Y. (2011). Examinations and educational opportunity in China: Mobility and bottlenecks for the rural poor. Oxford Review of Education, 37(2), 267-305. http://dx.doi.org/10.1080/03054985.2011.559387

He, J. M. (2000). China Gaokao report. Beijing: Huaxia Publishing House.

Hogwood, B. W., \& Gunn, L. A. (1984). Policy analysis for the real world. Oxford University Press.

Honig, M. I. (2006). Complexity and policy implementation challenges and opportunities for the field. In M. I. Honig (Ed.), New directions in education policy implementation: Conflicting complexity (pp. 1-24). Albany: State University of New York Press.

Karaman, A. C., \& Tochon, F. V. (2007). International student teaching in world language education: Critical criteria for global teacherhood. Critical Inquiry in Language Studies, 4(2), 237-264. http://dx.doi.org/10.1080/15427580701389714

Lian, J. P. (2011). Comparative research on human factors between SAT and Gaokao in China. Hubei Enrollment and Examination (in Chinese), 6, 36-39.

Lei, G. (2011). Retrospection and research on Chinese Gaokao system. China Academic Journal: Electronic Publishing House, 1-2.

Li, D., \& Edward, V. (2013). The impact of overseas training on curriculum innovation and change in English language education in Western China. Language Teaching Research, 17(4), 390-408. http://dx.doi.org/10.1177/1362168813494124 
Muthanna, A., \& Sang, G.

Li, D., \& Edward, V. (2014). English language teaching and educational reform in Western China: A knowledge management perspective. System, 47, 88-101. http://dx.doi.org/10.1016/j.system.2014.09.019

Liu, H., \& Wu, Q. (2006). Consequences of college entrance exam in China and the reform challenges. KEDI Journal of Education Policy, 3(1), 7-21.

Liu, Y. (2013). Meritocracy and the Gaokao: A system study of higher education selection and socio-economic participation in East China. British Journal of Sociology of Education, 34(5-6), 868-887. http://dx.doi.org/10.1080/01425692.2013.816237

Long, Y., \& Li, J. (2008). A sociological approach on the reform of existing Gaokao system. Studies of Youth in China (in Chinese), 4, 44-49.

Mcmillan, J. H., \& Schumacher, S. (2010). Research in education: Evidence-based inquiry (7th ed.). Pearson.

Paine, L., \& Zeichner, K. (2012). The local and global in reforming teaching and teacher education. Comparative Education Review, 56(4), 569-583. http://dx.doi.org/10.1086/667769

Pengsen, W. (2013). New way to reform Gaokao system. China Academic Journal: Electronic Publishing House, 70-76.

Pressman, J. L., \& Wildavsky. A. (1973). Implementation. Berkeley, CA: University of California Press.

Schroch, J. R. (2014). The Gaokao: The test where time stands still. University World News; the Global Window on Higher Education, China. Retrieved from http://www.universityworldnews.com/article.php?story=20140612091916875

Seidman, I. (2006). Interviewing as qualitative research: A guide for researchers in education and the social Sciences (3rd ed.) Teachers College, Columbia University.

Siegel, P. (June 12, 2007). Stressful times for Chinese students. Time INC. Network. Retrieved from http://content.time.com/time/world/article/0,8599,1631854,00.html

Strauss, J. C. (1994). Symbol and reflection of the reconstituting state: the examination Yuan in the 1930s. Modern China, 20(2), 211-238. http://dx.doi.org/10.1177/009770049402000204

Wang, Z. (2011). Upon the transformation of China's ancient test system and its enlightenment on today's reform of the National Entrance Exam to Colleges. Journal of Ningbo University (Educational Science Edition) (in Chinese), 33(2), 34-38.

Wang, E., \& Chan, K. W. (2005). Tilting score-line: geographical inequalities in admission scores to higher education in China. In F. Cai \& Z. Zhang (Eds.), The labor market in China's transition (pp. 237-266). Beijing, China Population Publishing House.

Wang, J. (2005). Youth culture, music, and cell phone branding in China. Global Media and Communication, l(2), 185-201. http://dx.doi.org/10.1177/1742766505054633

Wu, P. S. (2013). New way to reform Gaokao system. Exploration and Free Views (in Chinese), 4, 70-76.

Yan, C. (2014). 'We can't change much unless the exams change': Teachers' dilemmas in the curriculum reform in China. Improving Schools, 1-15.

Yan, L., \& Yao, L. (2010). A new idea for reforming the university entrance examination in China. Journal of Shanghai University (Social Sciences), 5(15), 132-143.

You, Z., \& Hu, Y. (2013). Walking a policy tightrope: The dilemma of balancing diversification and equality in Chinese college examination reform. Higher Education Policy, 26, 309-324. http://dx.doi.org/10.1057/hep.2013.3

Yu, L., \& Suen, H. K. (2005). Historical and contemporary exam-driven education fever in China. Korean Education Development Institute, Journal of Educational Policy, 2(1), 17-33.

Zhang, X., \& Zha, Y. (2010). On "abandoning examination" phenomenon of Gaokao. Hubei Enrollment and Examination (in Chinese), 4, 21-24.

Zhang, G., Zao, Y., \& Lei, J. (2012). Between a rock and a hard place: Higher education reform and innovation in China. Emerald, 20(4), 263-273. http://dx.doi.org/10.1108/10748121211272489

Zhao, Z., \& Ma, W. (2008). The enlightenments of US university enrollment policies on the reform of China's college matriculation examination. Journal of Liaoning Normal University (Social Science Edition) (in Chinese), 31(4), 74-77. 